\title{
Sorria: você está sendo jogado! Videogames, educação e moralidade dos ícones na mediapolis
}

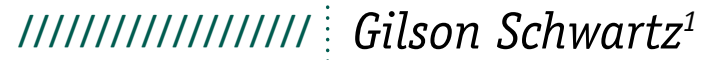

1. Professor do Programa de Pós-Graduação em Meios e Processos Audiovisuais da Escola de Comunicações e Artes da Universidade de São Paulo. E-mail: schwartz@usp.br 


\section{Resumo}

A transformação tecnológica a partir da qual se consolidou a digitalização da vida social nos últimos 50 anos colocou em novo patamar, sem propriamente superar, as tensões implícitas ao discurso da modernidade que se debate entre emancipação e condicionamento, liberdade e necessidade, inteligência e controle, gozo e manipulação. O ensaio identifica como essas questões são radicalizadas pela difusão dos videogames como prática cultural hegemônica na sociedade do espetáculo, abrindo novos horizontes para a economia do audiovisual e o desenvolvimento de uma "iconomia”.

Palavras-chave

Economia do audiovisual, educomunicação, videogames, mediapolis, iconomia.

\section{Abstract}

The technological transformation that results from the digitization of social life in the last 50 years takes the implicit tensions in the discourse of modernity to a new level, without properly overcoming the paradoxes between emancipation and conditioning, freedom and necessity, intelligence and control, authentic joy and psychological manipulation. This essay identifies how these issues are radicalized by the spread of videogames as a hegemonic cultural practice in the society of the spectacle while opening horizons for the audiovisual economy and the development of an "iconomy".

Audiovisual economy, educommunication, videogames, mediapolis, iconomy. 


\section{Games: cura infantil do capitalismo?}

O processo incessante de reprodução ilimitada de conteúdo, mecânica e depois digital, levou ao extremo (representado pelo pensamento de Marshal McLuhan) de considerar que o próprio meio é a mensagem, ou seja, a destruição da aura da obra de arte reflete uma mudança estrutural que destrói para sempre a relação de autenticidade entre as audiências e os artefatos culturais, a mimese torna-se um espetáculo essencial à reprodução do capital, novos mercados revelam a potência da economia audiovisual.

O cinema, não por acaso, é uma arte comumente designada como "indústria”. O videogame, como o rádio, o cinema e a TV, é a etapa mais avançada dessa tendência cultural, econômica e política marcante da sociedade da informação: não apenas o conteúdo mas também os principais "jardineiros" do conhecimento, os intelectuais (desde os professores do antigo "jardim de infância” ou "kindergarten"), perdem sua função frente a máquinas (hardware), sistemas (software) e redes (knoware).

A hipertrofia do conteúdo produzido e reproduzido sem aura por um meio voltado para si mesmo, sem centro nem direção, representa a morte dos intelectuais num altar que celebra incessantemente a sua própria sacralidade; a interface é a mensagem.

No entanto, a emergência dos videogames levou a uma percepção inédita na história das mídias. Ninguém falou em "cinemização" ou "televisionamento" da vida social, mas se tornou moeda corrente no debate contemporâneo sobre inovações 
e tendências em mercados de produtos e serviços audiovisuais a ideia de que vivemos uma "gamification" - tudo, em todas as áreas, pode ser traduzido numa narrativa interativa e imersiva que se torna a pré-condição da própria literacia e da capacidade de aprendizagem de todos os que frequentam esse "kindergarten" eterno que é a internet.

A referência nessa questão é Gee (2007), para quem as narrativas dos games devem ser colocadas em perspectiva psicolinguística, ou seja, não há “discursos naturais”. O resultado é uma pedagogia lúdica em que aprender equivale a criar e brincar. O papel dos educadores, das escolas e das práticas sociais é redefinido por sistemas de informação e comunicação cuja arquitetura responde cada vez mais aos imperativos de uma nova economia política do conhecimento em que toda criação e recreação exige domínio de interfaces digitais interativas, imersivas, audiovisuais.

Nessa perspectiva, a "gamificação" da educação e da sociedade como um todo corresponde a uma nova etapa do modelo competitivo de mercado cuja estética e valores alinham-se contínua e sistematicamente ao caldeirão igualmente mercadológico das moralidades pós-modernas. Há uma simetria entre a lógica procedural do computador e a retórica procedural da narrativa dos videogames (EGENFELDT-NIELSEN, 2013, p.160). Tornou-se portanto não apenas urgente mas também inevitável pensar criticamente a digitalização da vida social e ao mesmo tempo reconhecer o caráter lúdico dos objetos audiovisuais que estão na fronteira tecnológica e comercial do capitalismo atual. Observa-se uma evolução complexa (transmidiática) dos novos meios e processos de produção da imagem, da identidade e da inserção social, ampliando o debate sobre o lugar do indivíduo e da liberdade num capitalismo cujas cadeias de valor ampliam-se onde há produção e distribuição de ícones digitais.

\section{Arquiteturas lúdicas dos mercados audiovisuais}

Crianças e adolescentes são os principais portadores dessa vida digital anterior à escola e, cada vez mais, interpondo-se em relações familiares e sociais. O consumo de eletrônicos, basicamente 
computador e telefone celular, é o que mais cresce no Brasil. Em 2011, segundo a Pnad (Pesquisa Nacional por Amostra de Domicílios, do IBGE), os dados mostram que esse tipo de bem cresceu entre todas as idades e em todas as regiões do país. Nesse contexto, $41,9 \%$ das crianças e jovens entre 10 e 14 anos têm celular, um "país" com 10,9 milhões, crescendo a uma taxa de $43 \%$. Os jovens adultos, entre 25 e 29 anos, são os maiores consumidores de celulares $(83,1 \%)$. O computador com acesso à internet foi o bem durável que mais ganhou presença nos lares brasileiros. A ampliação do consumo de computadores e celulares supera a de carros, geladeiras e fogões, que se tornaram produtos subsidiados pelo governo para conter a crise. Como a renda aumenta menos que as taxas de aquisição de eletrônicos, especialistas afirmam que a população está se endividando para participar da chamada "inclusão digital".

Dos domicílios pesquisados pelo IBGE, 22,4\% tinham computador com acesso à internet em 2011, alta de 39,8\% em relação a 2009. Ao todo, 46,5 milhões de pessoas utilizaram o serviço em 2011. Os celulares estavam em 69,1\% dos lares em 2011.

Em suma, crianças representam pelo menos um quarto do mercado de consumo mais dinâmico da economia brasileira. Nesse contexto, estão postas as condições para uma expansão ainda mais intensa, nos próximos anos, dos mercados de conteúdos digitais com foco nesse público infantojuvenil e de jovens adultos, com destaque inquestionável para os jogos eletrônicos, os videogames. Como responderá a escola a essa mudança tão rápida e intensa? Se os jovens levam mais tempo para conseguir uma inserção produtiva na sociedade, enquanto os mais velhos ficam mais tempo ocupados, que interfaces, espaços e funções serão possíveis para que se consolide uma nova economia do ócio? É preciso "aprender a ficar ocioso", para o bem de todos?

A quantidade e a qualidade do trabalho, a abstração, a virtualidade, a flexibilidade e a criatividade que o caracterizam cada vez mais, a possibilidade de desestruturá-lo no tempo e no espaço, a progressiva confusão entre estudo e tempo livre aproximam o ócio do negócio pós-industrial. 
A “alegria do ócio” pós-industrial flagrada por Domenico de Masi aproxima-se ponto a ponto, quase como um decalque, à topografia dos mundos lúdicos digitais. Sonia Livingstone (2009) indica um conjunto de transformações (mudanças na estrutura do emprego, aumento da urbanização, novas relações entre mercado e Estado, ampliação do individualismo consumista, diversificação étnica das populações, transformação das relações de gênero e a redefinição do que seja um lar ou uma família) que torna ainda mais problemática, se é que não impede, a passagem da infância à vida adulta.

Novamente, o lugar, o tempo e o sentido da brincadeira, do tempo livre ou "desperdiçado", do jogo e principalmente do que chamamos de arquitetura lúdica do audiovisual ficam em primeiro plano.

Se há mais "oferta" de juventude na sociedade, o mundo adulto por sua vez volta-se com interesse comercial e político crescente para esse contingente populacional que a partir da mais tenra idade assume posição como sujeitos de uma cultura de consumo que dá ênfase à livre escolha assim como a modismos e estilos de vida intensamente sexualizados quando se trata de formação de identidade e socialização (esferas que até pouco tempo eram um domínio privado, essencialmente tradicional ou comunitário).

Giddens (1993) aponta para uma "democratização da esfera privada" em que as crianças ganham o direito de determinar e regular suas "condições de associação", que ganham nova "pureza”; a própria infância passa a ser continuamente renegociada em favor de novos modelos de autenticidade, intimidade, confiança, reciprocidade, reconhecimento e flexibilidade nos papéis assumidos em benefício de uma cultura narcísica e individualista. Nada parece mais proveitoso para a formação dessa nova criança que a universalização no espaço, no tempo e nas práticas pedagógicas da cultura do game.

Ser criança, em suma, equivale cada vez mais a construir seu próprio personagem para entrar em jogos de socialização e reconhecimento. Paradoxalmente, ser criança traduz-se cada vez mais no desafio de assumir responsabilidades que antecipam 
2. Cf. a pesquisa "TIC Crianças", em: http://www.cetic.br/usuarios/ criancas/2010/apresentacao-ticcriancas-2010.pdf. incertezas futuras, que obrigam essas crianças a lidar com riscos e insegurança do próprio status na medida em que os valores da família e da comunidade perdem completamente o sentido.

É portanto compreensível que os direitos da criança e do adolescente, os riscos da socialização digital e a construção de novas pedagogias passem a definir novas agendas e políticas públicas num mundo flutuante em que os adultos também se infantilizam.

Os dados² apontam que 27\% dos domicílios brasileiros têm acesso à internet (CGI.BR, 2010), sendo apenas 6\% na área rural. Apesar dessa limitação, é interessante observar que $51 \%$ das crianças entrevistadas relatam ter utilizado computador e $27 \%$ afirmam já ter utilizado a internet. Jogar e realizar atividades escolares (sobretudo busca) são as atividades que se destacam. Mas os jogos são citados por $90 \%$ das crianças.

Nenhuma novidade, ainda que o tema dos games mal tenha começado a entrar em nossas agendas de pesquisa, em especial na área pedagógica. Redes sociais também têm um apelo significativo: 29\% das crianças entrevistadas já usaram Orkut e Facebook, entre outros softwares de relacionamento.

Quanto à aquisição das habilidades para usar as TICs, os professores ainda são fundamentais segundo $37 \%$ das crianças da pesquisa, número que sobe para $53 \%$ na área rural. Entre as crianças entrevistadas, $60 \%$ usam o celular, aqui ainda com destaque para os jogos (84\%). Questões voltadas à segurança e participação da família também estão presentes no levantamento.

A cultura digital promove novas demandas e instaura dinâmicas que desafiam autoridades, controles e medidas de desempenho pessoal, social, educacional e profissional. Essa realidade traz desafios e oportunidades para os professores caso pretendam cerrar fileiras com seus alunos em defesa de práticas pedagógicas inspiradoras, capazes de ir além da mera transmissão de informações.

Entre os jovens entrevistados, é grande a expectativa de encontrar um professor mais próximo, mais "amigo", disposto a compartilhar 
(mais que "transmitir" ou "depositar") conhecimento de maneira lúdica e colaborativa. As novas tecnologias podem ajudar, mas também podem aprofundar os conflitos inevitáveis numa época de grande mudança tecnológica.

Na rede pública, o uso de celular é vetado. Muitos professores acham que brincar pode diminuir o seu "poder" ou "eficiência disciplinar", ou seja, consideram que a brincadeira é uma ameaça à autoridade e rejeitam in limine os games como dispositivos violentos e alienantes, resultados de uma sociedade do espetáculo que injeta a digitalização nas mais íntimas e primárias emoções de cada consumidor.

O estudo do Cetic.br ao menos sugere que a linguagem das novas gerações já é enriquecida por tecnologias de apropriação de conteúdos e vivências cujos resultados educacionais e culturais ainda são uma importante incógnita do processo.

É urgente a reinvenção do professor como um mentor, um parceiro inspirador e experiente na apropriação dos novos recursos tecnológicos em favor de práticas de aprendizagem mais criativas. Vencer esse desafio é o que nos levará nas escolas, nas empresas e na sociedade a uma vivência mais plena e democrática do conhecimento e da tecnologia no século 21.

Como dar conta desses desafios que se ampliam com a universalização da internet? Vamos acionar o botão do "pânico" (moral)? Vamos aderir às moralidades pós-modernas em que já não há sentido na busca de padrões abstratos de desenvolvimento da criança ao longo de estágios universalmente observáveis, à Piaget? Vamos adotar perspectivas mais sociométricas ou promover uma nova sociologia da infância cuja chave está num contexto de fluidez ou "liquidez" digital, à Vygotsky?

Como alerta Sonia Livingstone, todas as questões relativas à infância agora se recolocam diante do universo de problemas trazidos pela integração da infância à internet. A infância online traz riscos e oportunidades cuja compreensão é essencial também à análise e criação de novas práticas pedagógicas mediadas por tecnologias de informação e comunicação. 


\section{A criança na mediapolis: oportunidades e riscos}

$\begin{array}{ll}\text { Oportunidades } & \text { Riscos } \\ \text { Acesso a informação global } & \text { Conteúdo ilegal e pernicioso } \\ \text { Recursos educacionais } & \text { Pedófilos, estranhos, pervertidos } \\ \text { Redes sociais com amigos } & \text { Violência extremada ou sexual } \\ \text { Entretenimento, jogos, diversão } & \text { Conteúdo ofensivo e prejudicial } \\ \text { Criação de conteúdo pelos usuários } & \text { Material e atividades racistas e intolerantes } \\ \text { Participação cívica e política } & \text { Marketing e publicidade subreptícias } \\ \text { Privacidade para expressão da identidade } & \text { Preconceito e informação sem qualidade } \\ \text { Ativismo e engajamento comunitário } & \text { Manipulação de informações pessoais } \\ \text { Literacia e habilidades tecnológicas } & \text { Cyberbullying e assédio digital } \\ \text { Progresso na carreira e no trabalho } & \text { Cassinos, golpes, phishing (fraudes digitais) } \\ \text { Apoio pessoal, em saúde e sexualidade } & \text { Danos autoinfligidos (suicídio, anorexia) } \\ \text { Grupos de especialistas e redes de fãs } & \text { Invasões e abusos de privacidade } \\ \text { Compartilhamento de experiências } & \text { Atividades ilegais (hackers, piratas) }\end{array}$

Uma expressão resume os desafios e tensões desse novo contexto digital: nascemos e vivemos numa "mediapolis", termo criado por Roger Silverstone (2007) para indicar a preeminência desse "espaço de aparecimento mediado", um espaço público mediado em que a materialidade do mundo é construída principalmente pelo discurso e pela ação pública e comunicada eletronicamente, um espaço fraturado e fragmentado. É nesse espaço continuamente reconstruído que podemos ainda alcançar nossa própria humanidade, seja qual for a nossa localização.

\section{Uma “ensinagem” lúdica é possível?}

Que novas promessas surgem de uma aproximação entre o brincar digital e as transformações em curso no capitalismo em crise? É notório que a superação da crise econômica tem sido continuamente associada ao culto da inovação tecnológica, do capital intelectual e da criatividade como fontes de valor. 
A disseminação de games e, de modo geral, da educomunicação digital torna-se rapidamente a visão hegemônica em todo o mundo; governos apostam em ecossistemas educacionais como ferramentas de superação da crise financeira, que é também crise do trabalho e da identidade do sujeito autônomo que confia na ampliação incessante da democracia de massa e depende dela.

Vivemos hoje sob o efeito onipresente dos videogames (ou simplesmente games, mais um termo da língua inglesa que se integra à língua portuguesa). São brinquedos, jogos (ou "videojogos") que mobilizam nossa imaginação, alteram nossa identidade individual e coletiva, interferem em nossos afetos e emoções, porém sempre a partir de uma calculabilidade aperfeiçoada a cada onda de inovação tecnológica.

Seriam os games a etapa mais avançada e recente da racionalização do mundo, da vida e do pensamento ou estamos diante de uma inédita carnavalização do cotidiano, que alguns já denominam "gamificação" da sociedade? É a racionalidade que submete mais uma vez a diversão ao cálculo ou é o cálculo que finalmente se abre para a surpresa, para a diversão e até para a subversão do método cartesiano? Os “joguinhos" invadem as salas de aula e laboratórios de informática para condicionar de vez o aprendizado e robotizar a prática pedagógica a exemplo da automação industrial, bancária e do lazer de massa?

Numa sociedade em que a manipulação dos fluxos, ou seja, da relação para cada indivíduo entre tempo e projeto, confiança e ativismo, paciência e ousadia, repousa sobre uma formidável infraestrutura de telecomunicações que se pulverizou, se tornou ubíqua ou "pervasiva", as relações sociais atendem sobretudo aos imperativos da aceleração, do ganho de escala sem melhoria na qualidade da experiência de vida, do instrucionalismo ou construcionismo vinculado ao conhecimento declarativo.

Como evitar que o espetáculo nos transforme em espectadores sem espelho, sem olhos para olhar nem ouvidos para sintonizar outros fluxos, tempos e projetos ou para que determinadas áreas como saúde, educação e cultura conquistem os tempos, espaços e valorização que se esperam numa sociedade democrática? Jogamos ou somos jogados? 
De legislações repressoras à monetização da solidão massificada, a questão de monitorar e administrar os fluxos de informação (em especial os "gamificados"), ou seja, o desafio de regular a pulsão escópica num mundo que imita a realidade virtual (e não o contrário), é tão difícil e polêmica quanto, no passado, foram os projetos de controlar o Estado e o mercado.

Agora forma-se uma tríade, pois às tensões entre público e privado somam-se fatores que são produzidos especificamente pelas arquiteturas de informação em redes. Estado, mercado e rede formam assim uma nova tríade a partir da qual é necessário repensar, discutir e implementar novos meios de fazer a crítica aos próprios meios, que, em princípio, nada mais seriam além da interface neutra a facilitar a emissão e a recepção de dados, informações, imagens e conteúdos.

À questão do público e do privado soma-se outra, cujo trato é ainda mais delicado e polêmico: a questão da intimidade. Se as redes hiperpotenciam os limiares quantitativos, as escalas e as intensidades de experiências de produção e consumo da era industrial, são também as redes que exibem muito do empreendedorismo, da liberdade de comunicação e expressão, da criatividade artística e da legitimação de novos costumes, hábitos e práticas que seriam eternamente provincianas sem a emergência das redes.

Entre o ganho de escala e de impactos quantitativos e a ampliação de direitos, da diversidade e da sustentabilidade acumulam-se tensões e desafios inéditos que exigem revisão contínua de padrões, normas, regras e definições do que seja normal ou patológico, acelerado ou calmo, efetivo ou afetivo. Falam muito do estresse e dos distúrbios da adição a games, porém o efeito acelerador da tecnologia sobre todas as atividades, em especial as escolares, é igualmente preocupante.

Podem os processos de aprendizagem converter-se numa "ensinagem" colaborativa em redes em que o pensar, o fazer e o brincar conduzam a mais conhecimento e cuidado, antes de condenar as massas a novas formas de controle panóptico e manipulação da atenção? 


\section{Referências}

DE MASI, D. O futuro do trabalho: fadiga e ócio na sociedade pósindustrial. Rio de Janeiro: UnB; José Olympio, 2009.

EGENFELDT-NIELSEN, S., SMITH, J. H., TOSCA, S. P. Understanding video games: the essential introduction. London: Routledge, 2013.

GEE, J. P. What video games have to teach us about learning and literacy. New York: Palgrave MacMillan, 2007.

GIDDENS, A. The transformation of intimacy: sexuality, love and eroticism in modern societies. Cambridge: Polity Press, 1993.

LIVINGSTONE, S. Children and the internet. Cambridge: Polity Press, 2009.

SILVERSTONE, R. Media and morality: on the rise of the mediapolis. Cambridge: Polity Press, 2007. 